\title{
Dynamic analysis of elevated viaducts of Doha metro green line
}

\author{
Essam Ayoub ${ }^{1}$, Sameh Mehanny ${ }^{1, a}$, Charles Malek ${ }^{2}$ and Gamal Helmy ${ }^{2}$ \\ ${ }^{1}$ Cairo University, Structural Engineering Department and Dar Al Handasah, Bridge Department, Cairo, Egypt \\ ${ }^{2}$ Dar Al Handasah, Bridge Department, Cairo, Egypt
}

\begin{abstract}
The 2.7 kilometers double track elevated viaducts of Doha metro green line, currently under construction, consist of cast-in-situ and precast segmental simply supported spans ranging from 20 to $35 \mathrm{~m}$ and continuous cast-insitu two and three spans (30-57 m), (50-51-44 m) and (37-68-37 m) U-trough decks. The non-typical configuration of the continuous span arrangements was imposed to the designer by existing underneath utilities and infrastructures. In order to ensure the passenger comfort and traffic safety by preventing track instability during train operation for this special landmark project, performing a dynamic analysis was vital. The dynamic analysis focuses on the vertical accelerations and vertical displacements as well as lateral frequencies of vibration. All simply supported spans as well as the continuous spans of the project are considered. The real train of the project composed of 6 vehicles with a total length of $120 \mathrm{~m}$ and with actual axle loads (maximum axle load of $160 \mathrm{kN}$ with 4 axles per vehicle) is adopted in the dynamic analysis. The analysis is carried out using both direct time integration of the equation of motion and modal time history analysis for different train speeds ranging from $60 \mathrm{~km} / \mathrm{hr}$ to the maximum permissible speed along the metro line $(160 \mathrm{~km} / \mathrm{hr})$ with the maximum operating speed ranging from 100 to $130 \mathrm{~km} / \mathrm{hr}$. For each train speed the maximum vertical acceleration and the maximum vertical deflection are monitored using the CSI bridge software and are compared to the allowable values given in EN 1991-2 and EN 1990-Annex 2. According to relevant Euronorm requirements, the vertical accelerations and the vertical deflections were found acceptable for all segments of the elevated viaduct.
\end{abstract}

\section{Introduction}

One of the main design issues associated specifically to the design of bridges and structures in railway lines are the dynamic effects due to moving loads from train traffic. This has been studied since the early days of railways [1], as well as in more recent works (e.g., [2 \& 3]). Some design codes [4-6] for design of railway bridges consider the dynamic response simplistically through an impact factor, which represents the increase in the dynamic response with respect to the static response for a single moving load.

Railway lines may pose dynamic problems of higher order, due to the possibility of resonance, considering the typical distances between axles in railway coaches and the main eigen frequencies of bridges. Resonance occurs when the excitation frequency coincides with that of the fundamental vibration mode of the bridge. In case of resonance, excessive bridge deformations can endanger traffic by creating unacceptable changes in vertical and horizontal track geometry, as well as excessive rail stresses and vibrations in bridge structures. Excessive deformations can also affect the loads imposed on the track/bridge system, and hence create conditions which cause passenger discomfort.

\section{Methods for dynamic analysis of railway bridges}

Dynamic effects in general and the possibility of resonance in particular require a dynamic analysis for the design of railway bridges. Moving load finite element models provide a general methodology. Continuous deck bridges lead generally to a less marked resonance, although a dynamic analysis is still necessary for them.

Dynamic analysis techniques vary from (1) static envelopes generated through equivalent static analysis with dynamic (i.e., impact) factor, $\Phi$; to (2) simple frequency analysis conducted in order to place limits on fundamental vibrational characteristics (i.e., mode shapes) of the bridge and aerial structures aiming to ensure well-proportioned structures, and minimize resonance effects; to (3) conventional dynamic analysis of the bridge deck under moving loads; and finally (4) more sophisticated and all-inclusive dynamic analysis considering vehicle-structure (i.e., train-bridge) interaction.

The basic method followed up to now in the existing engineering codes for railway bridges [4 and 6] has been that of the impact factor, generally represented as $\Phi$. Such coefficient represents the dynamic effect of (single)

\footnotetext{
${ }^{a}$ Corresponding author: sameh.mehanny@stanfordalumni.org
} 
moving load, but does not include resonant dynamic effects. The applicability of the impact factor $\Phi$ is nonetheless subject to some restrictions, involving bounds on $f_{o}$ as well as a maximum train speed of 200 $\mathrm{km} / \mathrm{h}$ [4], where $f_{0}$ is the first natural bending frequency of deck (vertical) vibration. Should a structure fall within the desired vertical frequency range, less extensive static and dynamic analysis will be required at preliminary and final design stages. Should a structure fall outside of the desired vertical frequency range, more extensive static and dynamic analysis will be required at preliminary and final design phases.

Conventional dynamic analysis of the bridge is generally based on time integration of the dynamic equations, subject to a series of moving loads of constant values, representative of each axle of a given train. The structure is first discretized using a finite element method or a more particular bar (frame element) technique, arriving to a vector of $\mathrm{N}$ (unknown) nodal displacements. The model for the structure may be hence analyzed either through a direct integration of the complete system or through a modal time history analysis. The latter is sometimes preferred for a reduction of the degrees of freedom to be considered. Modal reduction reduces substantially the number of equations to integrate, and may be performed through an approximate numerical procedure to obtain the eigen modes of vibration. This capability is provided by most commercial finite element programs. Alternatively the modal reduction may be achieved through an analytical (closed form) calculation, for certain cases of simple structures.

More sophisticated and comprehensive dynamic analysis involves the consideration of the vertical motion of the vehicles with respect to the bridge deck which allows for a more realistic representation of the dynamic overall behaviour. The train is no longer represented by moving loads of fixed value, but rather by point masses, bodies and springs which represent wheels, bogies and coaches. In some cases these models may have a nonnegligible influence on the dynamic response of the bridge. The high level of detail is however not always necessary. Often simplified models may be employed in which for each axle only the primary suspension, equivalent unsprung and sprung masses are considered. In such models each axis is independent from the rest, thus neglecting the coupling provided by the bogies and vehicle box, as well as the rocking motion of the vehicle box. The consideration of vehicle-structure interaction often reduces the dynamic response of the bridge as in [3]. This may be explained considering that part of the energy from the vibration will be transmitted from the bridge to the vehicles. In short span bridges (i.e., $\mathrm{L} \leq$ $30 \mathrm{~m})$ this may produce a reduction of up to $30 \%$ [3]. However, in longer spans or in continuous deck bridges the reduction will generally be small. As a consequence, it is not generally necessary to perform dynamic analysis with interaction, except for particular cases. From a dynamic point of view, continuous deck bridges exhibit a much different (and generally lower) response to traffic loads than isostatic (i.e., simply supported) bridges. This is due to the fact that at any time the response of the bridge is governed not by one vibration mode but by a large number of modes. These modes are excited positively or negatively by traffic loads at the various spans, and the sum of the responses cancels much of their effects. In line of the above, and for practicality without loss of accuracy, the present study focuses on conventional dynamic analysis of the bridge deck under real train moving loads and ignores representing trainbridge interaction.

\section{Description of the bridge segments considered in the present work}

Due to the limitations of the paper length, comprehensive dynamic analysis were applied on only three selected bridge segments of the elevated viaduct of Doha metro green line. Each of the selected segments is bounded by expansion joints. The first two segments are simply supported bridges with 32 and $23 \mathrm{~m}$ spans; while, the third one is two-span continuous bridge having $39.5 \mathrm{~m}$ and $57.1 \mathrm{~m}$ adjacent spans. As shown in figure 1 , the simply supported segments have U-shape section hosting two tracks and resting on four elastomeric bearings (two at each end) and with $2.2 \mathrm{~m}$ and $2 \mathrm{~m}$ depths at support and at mid-span, respectively. At mid-span the web as well as the slab thicknesses are $35 \mathrm{~cm}$; while, at support, the web and the slab thicknesses are $60 \mathrm{~cm}$ and $50 \mathrm{~cm}$, respectively. The elastomeric bearings are resting on pier heads of $9.7 \times 5.6 \mathrm{~m}$. The top of pier is of $1.7 \times 1.7 \mathrm{~m}$ dimensions and sloped in the downward direction using a $2^{\circ}$ angle. Figure 2 shows the elevation and the different cross sections of the two-span continuous segment. These sections are located at the monolithic pier, at bearing support and at transition areas within the $39.5 \mathrm{~m}$ and the $57 \mathrm{~m}$ spans. At monolithic pier the section is of a box shape overtopped with the typical U-section of the project, at bearing support is of $U$ shape, while at transition sections is of U-section with dropped slab.



1a. Elevation of $32 \mathrm{~m}$ simply supported span

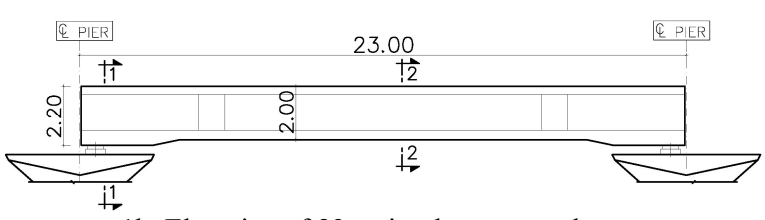

1b. Elevation of $23 \mathrm{~m}$ simply supported span

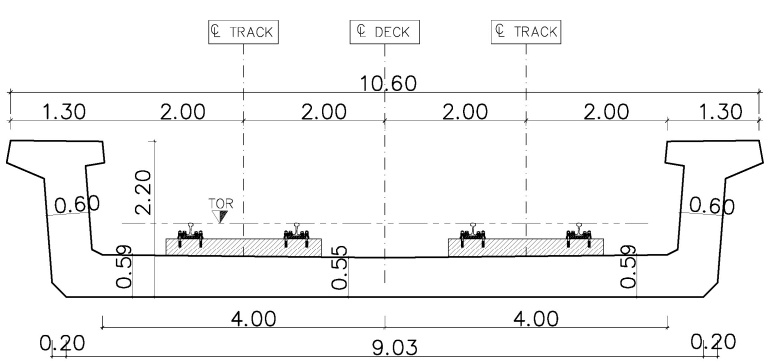

1c. Section (1-1) 




1d. Section (2-2)

Figure 1. Description of the simply supported spans $32 \mathrm{~m}$ and $23 \mathrm{~m}$

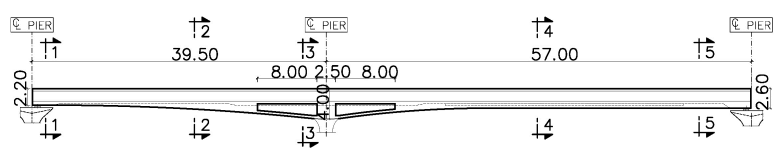

2a. Elevation

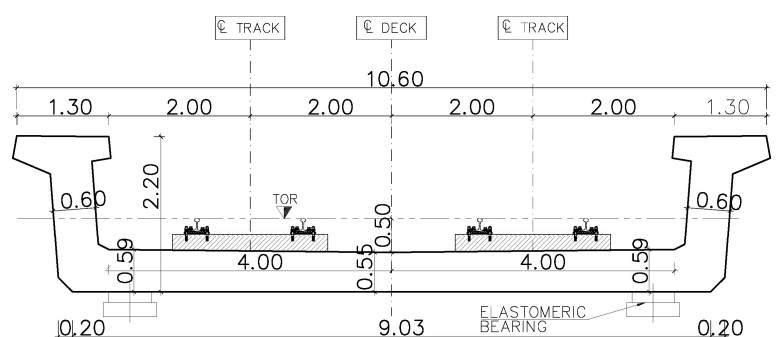

2b. Section (1-1)

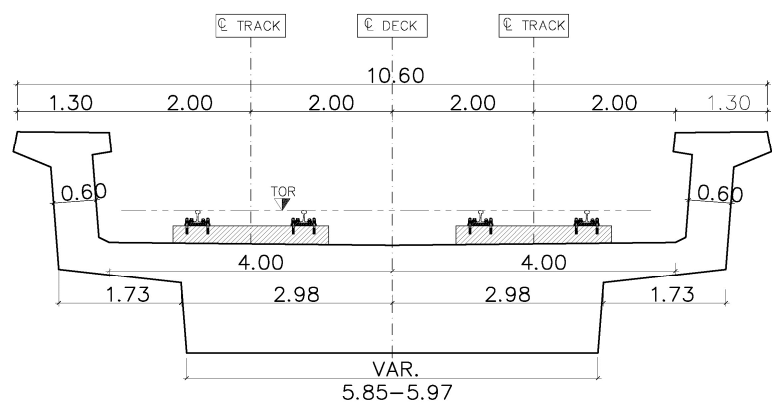

2c. Section (2-2)



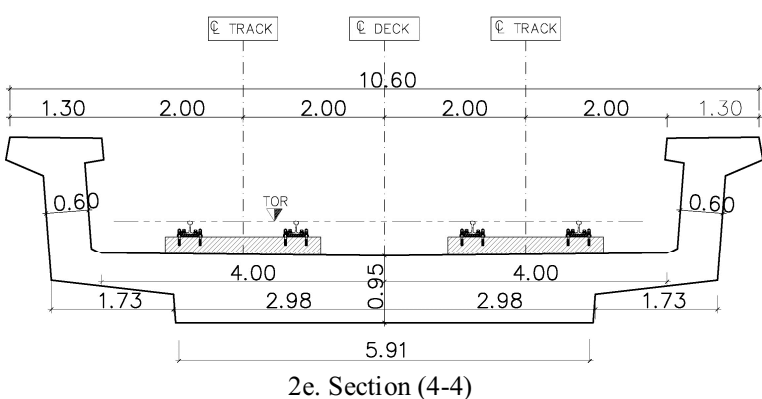

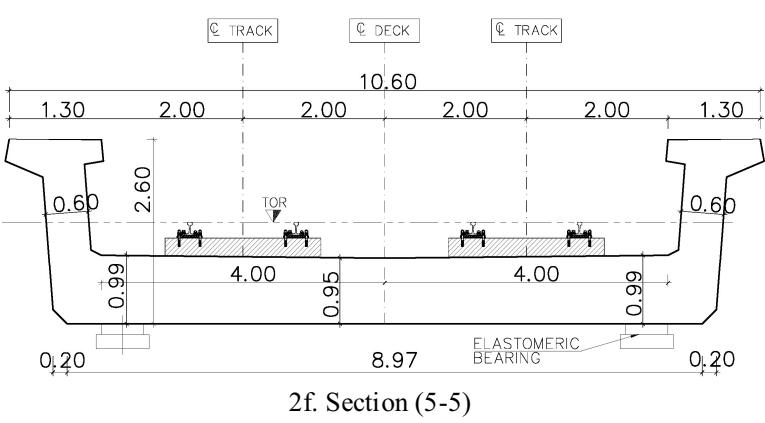

Figure 2. Description of the $39.5 \mathrm{~m}-57 \mathrm{~m}$ two-continuous spans Segment

\section{Code relevant limitations and requirements}

In order to deal with this sensitive dynamic problem, Eurocode [5] has imposed some requirements related to limiting (a) the vertical accelerations of the deck in order to avoid unacceptable reduction in wheel rail contact forces (EN 1990: A2.4.4.2.1); (b) the vertical deflection of the deck throughout each span in order to ensure acceptable vertical track radii and generally robust structures (EN 1990: A2.4.4.2.3(3)); and (c) the first natural frequency of lateral vibration of the span to avoid the occurrence of resonance between the lateral motion of vehicles on their suspension and the bridge (EN 1990: A2.4.4.2.4(3)). Furthermore, checks on bridge deformations are performed as per code requirements to satisfy passenger comfort; namely, vertical deflection of the deck shall be capped to limit coach body acceleration in accordance with EN 1990 - A2.4.4.3. The limits given in A2.4.4.2 and A2.4.4.3 take into account the mitigating effects of track maintenance (for example to overcome the effects of the settlement of foundations, creep, etc.).

In specific terms, to ensure traffic safety where a dynamic analysis is sought, the verification of maximum peak deck acceleration due to rail traffic actions shall be regarded as a traffic safety requirement checked at the serviceability limit state for the prevention of track instability. The maximum peak values of bridge deck acceleration calculated along each track shall not exceed $5.0 \mathrm{~m} / \mathrm{s}^{2}$ for direct fastened tracks with the track and structural elements designed for speedy traffic. In addition, in accordance with EN 1991-2 [4], the maximum total vertical deflection measured along any track due to rail traffic actions should not exceed L/600. To limit vertical vehicle acceleration to the values given 
in A2.4.4.3.1(2), values are given in that clause for the maximum permissible vertical deflection along the center line of the track of railway bridges as a function of the span length $\mathrm{L}$, the train speed $\mathrm{V}$, the number of spans and the configuration of the bridge (simply supported beam, continuous beam, etc.) - Fig. A2.3. The vertical deflections should be determined considering the relevant load model (or the real train configuration) multiplied by the dynamic factor $\Phi$. For bridges with two or more tracks only one track should be loaded. The limiting values of $\mathrm{L} / \delta$ given in Figure A2.3 are given for vertical acceleration inside the coach, $b_{v}=1.0 \mathrm{~m} / \mathrm{s}^{2}$ which may be taken as providing a "very good" level of comfort. The values of $\mathrm{L} / \delta$ given in Figure A2.3 are given for a succession of simply supported beams with three or more spans. For a bridge comprising of either a single span or a succession of two simply supported beams or two continuous spans the values of $\mathrm{L} / \delta$ given in Figure A2.3 should be multiplied by 0.7 . For continuous beams with three or more spans the values of $L / \delta$ given in Figure A2.3 should be multiplied by 0.9 .

To recap, for typical structures limiting the maximum vertical span deflection and deck acceleration provides the sufficient guidance for passenger comfort. Passenger comfort is a final design issue. Should a structure fall outside of the desired vertical frequency range as mentioned before, then passenger comfort analysis will be required at final design stage. On the other hand, for exceptional structures (e.g., long span structures, continuous beams with widely varying span lengths, and spans with wide variation in stiffness), passenger comfort analysis may be required, as determined by the relevant Authority.

\section{Dynamic analysis results for the bridge segments considered in the present paper}

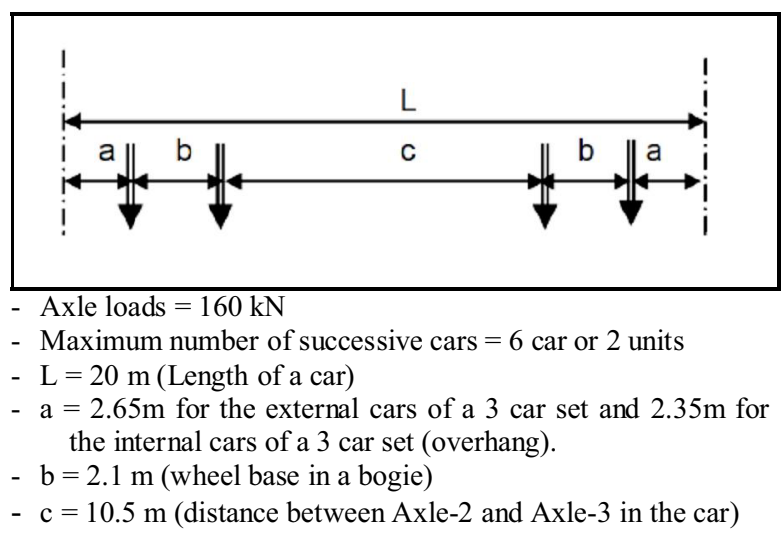

Figure 3. The actual train of the project

A comprehensive dynamic analysis was carried out on the three selected bridge segments of Doha elevated viaduct described above in section 4 (two simply supported and one two-span continuous bridge segments). Each bridge segment is first discretized using one dimensional finite element method (conventional spine model). The segment is then subjected to moving loads representing the actual train of the project (figure 3 ). The train is composed of 6 vehicles with a total length of $120 \mathrm{~m}$ and with maximum axle load of $160 \mathrm{kN}$ with 4 axles per vehicle. Only one track is loaded by this Real train while performing dynamic analysis as required by EN 1990-A2.4.4.3.2(2) and EN 1991-2 Cl. 6.4.6.1.2(3).

Two major methods are available to solve the dynamic equations; namely, direct time integration and modal time history analysis. The dynamic analysis results shown below for the above three bridge segments are based on the direct time integration method using $1 \%$ damping (refer to Table 6.6 Cl. 6.4.6.3.1(3) EN 1991-2). However, the two-span bridge segment was also solved using the modal time history analysis and results are compared to the dynamic results obtained from the time integration method. In the present paper, the dynamic results focus on the vertical displacements and the vertical accelerations due to different train speeds ranging from 60 to $160 \mathrm{~km} / \mathrm{h}$, as well as on the fundamental lateral frequency and the vertical (bending) frequencies of the viaducts' deck. Figures 4 and 5 show the maximum displacement and the maximum acceleration versus the train speed for the $32 \mathrm{~m}$ and the $23 \mathrm{~m}$ simple span bridge segments, respectively. Figures 6 and 7 display the maximum displacement and the maximum acceleration versus the train speed for the two-span continuous segment $(39.5$ and $57 \mathrm{~m})$ using the time integration and the modal time history analysis methods, respectively.

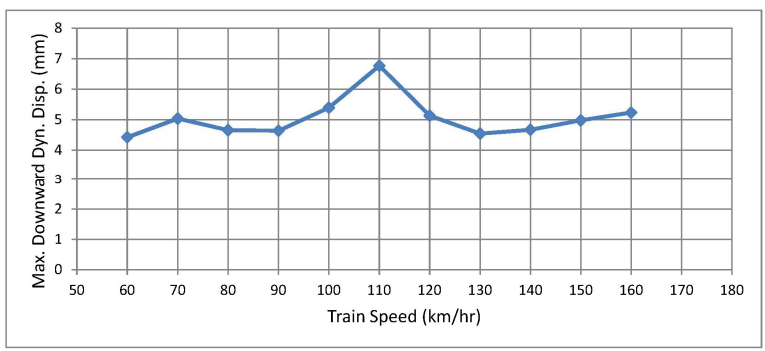

4a. Maximum downward dynamic displacement

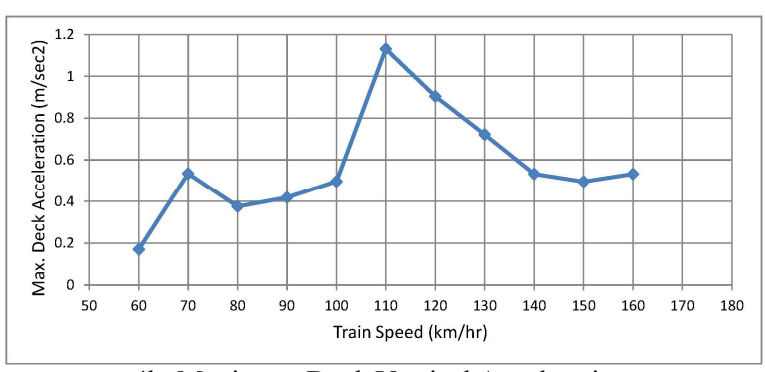

4b. Maximum Deck Vertical Acceleration

Figure 4. Max. displacement and max. acceleration versus train speed for the $32 \mathrm{~m}$ simply supported span 


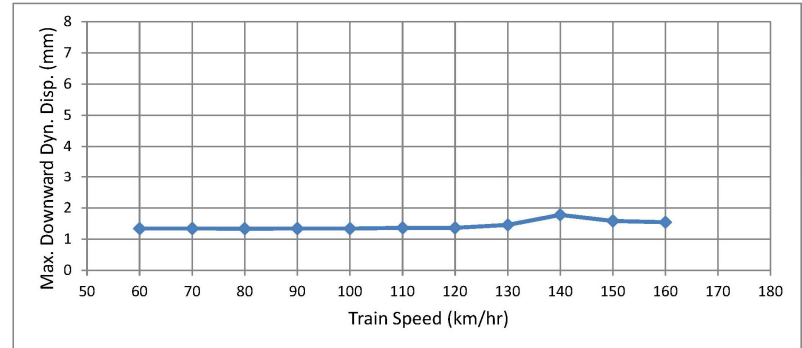

5a. Maximum downward dynamic displacement



5b. Maximum deck vertical acceleration

Figure 5. Max. displacement and max. acceleration versus train speed for the $23 \mathrm{~m}$ simply supported span



6a. Maximum dynamic displacement (39.5m-span)

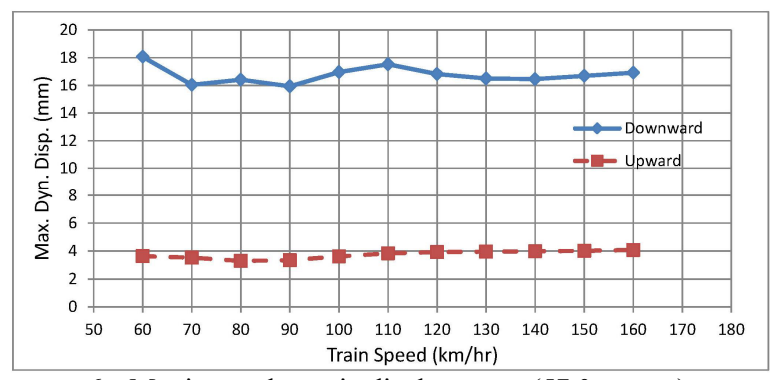

6c. Maximum dynamic displacement (57.0m-span)

Figure 6. Max. displacement and max. acceleration versus train speed for the $39.5 \mathrm{~m}-57 \mathrm{~m}$ two-continuous spans segment using direct time integration of the equation of motion

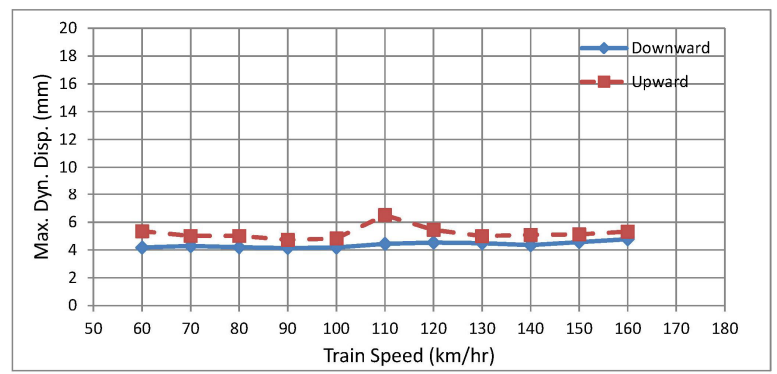

7a. Maximum dynamic displacement (39.5m-span)

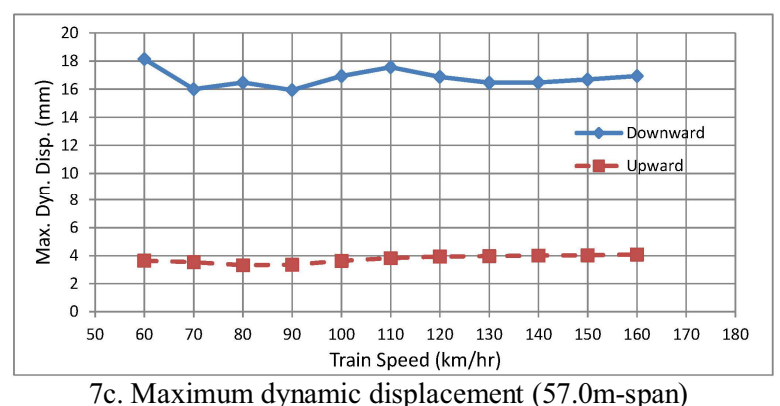

c. Maximum dynamic displacement (57.0m-span)

Figure 7. Max. displacement and max. acceleration versus train speed for the $39.5 \mathrm{~m}-57 \mathrm{~m}$ two-continuous spans segment using modal time history analysis (vertical modes considered mobilize $97 \%$ of total mass)



6b. Maximum deck vertical acceleration (39.5m-span)

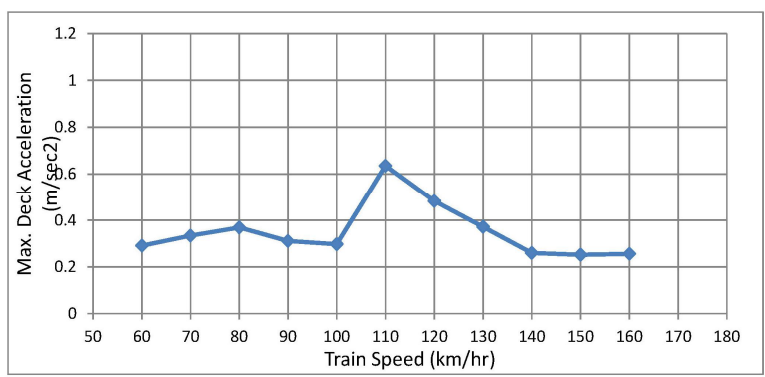

6d. Maximum deck vertical acceleration (57.0m-span)

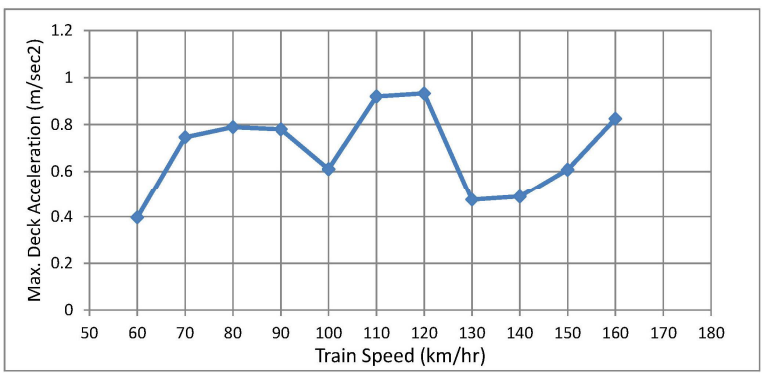

7b. Maximum deck vertical acceleration (39.5m-span)



$7 \mathrm{~d}$. Maximum deck vertical acceleration ( $57.0 \mathrm{~m}$-span)
eed for the $39.5 \mathrm{~m}-57 \mathrm{~m}$ two-continuous spans segment (n) 
Table 1 presents the lateral fundamental frequencies of vibration and table 2 provides the (few) first most effective vertical (bending) frequencies for the three viaduct segments studied in this paper.

Table 1. First lateral mode of vibration of the studied segments.

\begin{tabular}{|c|c|}
\hline Viaduct Segment & $\begin{array}{c}\text { First Lateral Mode of } \\
\text { Vibration }(\mathbf{H z})\end{array}$ \\
\hline Simple Span $-32 \mathrm{~m}$ & 5.81 \\
\hline Simple Span $-23 \mathrm{~m}$ & 8.92 \\
\hline Continuous 2-span $39.5-57 \mathrm{~m}$ & 3.87 \\
\hline
\end{tabular}

Table 2. Effective vertical (bending) frequencies for the studied viaduct segments.

\begin{tabular}{|c|c|c|}
\hline Mode \# & $\begin{array}{c}\text { Vertical (Bending) } \\
\text { Frequency (Hz) }\end{array}$ & $\begin{array}{c}\text { Modal Participation } \\
\text { Mass Ratio (\%) }\end{array}$ \\
\hline \multicolumn{3}{|c|}{ Simple Span-32m } \\
\hline 1 & 3.27 & 81 \\
\hline \multicolumn{3}{|c|}{ Simple Span-23m } \\
\hline 1 & 6.29 & 74 \\
\hline \multicolumn{3}{|c|}{ Continuous 2-span 39.5-57m } \\
\hline 1 & 1.72 & 19 \\
\hline 2 & 3.33 & 37 \\
\hline 3 & 5.39 & 2 \\
\hline 4 & 9.62 & 12 \\
\hline 5 & 10.96 & \\
\hline
\end{tabular}

\section{Discussions of the dynamic results of the selected bridge segments of the current viaduct project}

According to the dynamic results given in section 5 above many interesting observations can be made as follows:

\subsection{Typical simple span $-32 \mathrm{~m}$}

1. For the typical simple span with a $32 \mathrm{~m}$ length having an open U-section, the maximum downward displacement obtained from the dynamic analysis under one loaded track of the real train of the project shown above in figure 3 varies with the train speed to be $4.4 \mathrm{~mm}$ for the minimum applied train speed $60 \mathrm{~km} / \mathrm{hr}$ and 5.23 $\mathrm{mm}$ for the maximum permissible train speed along the Green line metro of $160 \mathrm{~km} / \mathrm{hr}$ (figure 4a above). However, the maximum downward deflection occurs at $110 \mathrm{~km} / \mathrm{hr}$ (i.e., in the range of expected maximum operating speeds of 100 to $130 \mathrm{~km} / \mathrm{hr}$ ) with a value of $6.8 \mathrm{~mm}$. This value which corresponds to "span/4638" for the $32 \mathrm{~m}$ simple span is much lower than the value retrieved from EN 1990 Annex A2 figure A2.3 $(\approx$ span/600) preset to guarantee passenger comfort.
2. On the other hand, the maximum vertical acceleration of the $32 \mathrm{~m}$ simple span obtained from the dynamic analysis is $1.13 \mathrm{~m} / \mathrm{sec}^{2}$ and this value also corresponds to a train speed of 110 $\mathrm{km} / \mathrm{hr}$ (figure $4 \mathrm{~b}$ above). According to EN 1990 - Annex A2, Article A2.4.2.2.1(4)P, the vertical acceleration should not exceed $5 \mathrm{~m} / \mathrm{sec}^{2}$ for direct fastened tracks as adopted in Doha metro Green line. This limit is preset by the code in order to ensure traffic safety. Where a dynamic analysis is necessary, the verification of maximum peak deck acceleration due to rail traffic actions shall be regarded as a traffic safety requirement checked at the serviceability limit state for the prevention of track instability.

3. Finally, the fundamental lateral frequency of vibration for this simply supported typical segment of the viaduct as retrieved from the dynamic analysis output (table 1) is $5.81 \mathrm{~Hz}$ which is significantly larger than $1.2 \mathrm{~Hz}$ (minimum frequency imposed by EN 1990 Annex A2, Article A2.4.4.2.4(3) as a supplementary criterion for traffic safety).

\subsection{Typical simple span -23 m}

1. For the typical simple span having $23 \mathrm{~m}$ length and an open U-section, the maximum downward displacement obtained from the dynamic analysis under one loaded track of the real train load of the project shown above in figure 3 varies with the train speed to be $1.34 \mathrm{~mm}$ for the minimum applied train speed $60 \mathrm{~km} / \mathrm{hr}$ and 1.54 $\mathrm{mm}$ for the maximum applied train speed 160 $\mathrm{km} / \mathrm{hr}$ (figure 5a above). However, the maximum downward deflection occurs at 140 $\mathrm{km} / \mathrm{hr}$ with a value of $1.8 \mathrm{~mm}$. This speed is slightly higher than the maximum operating speed range of the metro line but is still below the maximum permissible speed of $160 \mathrm{~km} / \mathrm{hr}$ specified along the line. This value which corresponds to "span/12778" for the $23 \mathrm{~m}$ simple span is much lower than the value retrieved from EN 1990 Annex A2 figure A2.3 $(\approx \operatorname{span} / 1000)$.

2. The maximum vertical acceleration of the $23 \mathrm{~m}$ simple span obtained from the dynamic analysis is $1.03 \mathrm{~m} / \mathrm{sec}^{2}$ and this value corresponds to a train speed of $150 \mathrm{~km} / \mathrm{hr}$ (figure $5 \mathrm{~b}$ above) - a speed which is very close to the maximum permissible speed along the Green line. As highlighted above, according to EN1990 Annex A2 - Article A2.4.2.2.1(4)P, this vertical acceleration should not exceed $5 \mathrm{~m} / \mathrm{sec}^{2}$ which is satisfied herein by a considerable margin.

3. Finally, the fundamental lateral frequency for this segment as retrieved from the dynamic analysis output (table 1) is $8.92 \mathrm{~Hz}$ which is 
considerably larger than $1.2 \mathrm{~Hz}$ (minimum frequency imposed by EN 1990 - Annex A2, Article A2.4.4.2.4(3)).

\subsection{Continuous two-span viaduct segment - 39.5-57 m}

For completeness and for the sake of sensitivity analysis targeting reliable results taking into consideration the non-typical span arrangements of this segment of the viaduct as dictated by the underneath existing utilities and infrastructures, dynamic analysis under the real train with various speeds has been performed according to two solution techniques. The first is through direct integration of the equation of motion (for the corresponding results refer to figure 6); while the second is based on modal time history analysis (results are given in figure 7). In order to warrant accuracy of the results in the latter analysis technique an appropriate number of vertical (i.e., bending) modes of vibration is considered (namely, a number of modes that guarantees above $90 \%$ of the total vibrating mass of the viaduct is mobilized). This entails considering vertical modes of vibration associated with rather high frequencies that exceed $11 \mathrm{~Hz}$ as could be inferred from table 2 .

1. For this continuous two-span segment with the non-typical span arrangement of 39.5-57 m, downward and upward deflections appeared in the dynamic results for each span (figures $6 a, 6 c$, $7 \mathrm{a}$ and $7 \mathrm{c}$ above) due to the continuity effect. It is observed that downward deflection in the $57 \mathrm{~m}$ is much higher than the upward deflection; while the opposite occurs for the $39.5 \mathrm{~m}$ span as expected. However, all deflections are within the allowable values imposed by EN 1990 Annex A2 figure A2.3. Also it is noticed that the dynamic results corresponding to the vertical deflections obtained from both time integration and the modal time history analysis methods are very close. This is an anticipated observation since we are looking into an integrated response (i.e., deflections) where any discrepancies resulting from computational inaccuracy are suppressed.

2. Referring to figs. $6 \mathrm{~b} \& 6 \mathrm{~d}$ (direct integration of the equation of motion) and figs. $7 \mathrm{~b} \& 7 \mathrm{~d}$ (modal time history analysis), it is noted that the maximum vertical accelerations for each of the two spans are less than or at maximum equal to $1 \mathrm{~m} / \mathrm{s}^{2}$ for all different train speeds with the maximum value associated with the range of the maximum operating speeds (100 to $130 \mathrm{~km} / \mathrm{hr}$ ). Reported maximum vertical accelerations from dynamic analysis are significantly below the maximum limit of $5 \mathrm{~m} / \mathrm{s}^{2}$ pre-set by EN1990 Annex A2, Article A2.4.2.2.1(4)P to ensure traffic safety.

3. Finally, the fundamental lateral frequency of the two-span continuous segment is $3.87 \mathrm{~Hz}$ (table 1 above) which is satisfactory since it is larger than the code predetermined limit of $1.2 \mathrm{~Hz}$.

\section{Conclusion}

In conclusion, the dynamic analysis of the elevated viaducts of Doha metro green line hosting double tracks with actual trains having maximum axle load of $160 \mathrm{kN}$ is essential to ensure that the structure, as-designed, fulfils the requirements imposed by EN for passenger comfort under actual (i.e., real) train moving loads. The dynamic analysis results were carried out for train speeds varying from 60 to $160 \mathrm{~km} / \mathrm{hr}$. The study focuses on the vertical deflections, the vertical accelerations, the fundamental lateral and vertical (bending) frequencies. Computational solution of the dynamic equations describing the problem is based on the direct time integration method as well as the modal time history analysis method. It was noticed that both methods lead to almost the same dynamic results. The complete and comprehensive dynamic analysis reveals that all dynamic results satisfy all EN requirements for all different segments of the project. Hence, the viaduct fulfils not only the static safety/serviceability demands (stresses, deflection, etc.) but also the dynamic effects such as avoiding resonance and assuring passenger comfort.

\section{References}

1. S.P. Timoshenko and D.H. Young. Vibration problems in engineering. Van Nostrand, NY (1955)

2. L. Fryba. Dynamics of railways bridges. Thomas Telford (1996)

3. J.M. Goicolea. Dynamic loads in new engineering codes for railway bridges in Europe and Spain. Workshop on Bridges for High-Speed Railways, Porto, 3-4 June (2004)

4. Comité Européen de Normalisation, EC 1 - CEN (2003). Actions on structures. Part 2: traffic loads on bridges. European Committee for Standardization, EN 1991-2, Brussels, Belgium (2003)

5. Comité Européen de Normalisation, EC $0-\mathrm{CEN}$ (2005). Basis of structural design. Annex A2: applications for bridges. European Committee for Standardization, EN 1990, Brussels, Belgium (2005)

6. Union Internationale des Chemins de Fer (UIC), UIC Code 776-1 R: Charges à prendre en considération dans le calcul des ponts-rails, (1979). 